\title{
PELATIHAN PENGELOLAAN PERSEDIAAN, PEMASARAN DAN PEMBUKUAN SEDERHANA UNTUK UMKM DESA PAKIS KECAMATAN KUNJANG KABUPATEN KEDIRI
}

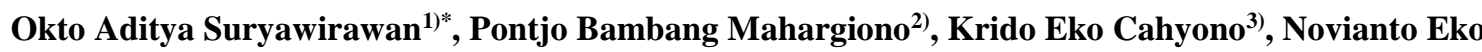 \\ Nugroho ${ }^{4}$ \\ 1,2,3,4 Sekolah Tinggi Ilmu Ekonomi Indonesia (STIESIA) Surabaya \\ *email: oktoaditya@stiesia.ac.id
}

\begin{abstract}
Abstrak
UMKM di Indonesia khususnya di daerah yang masih tergolong terpencil seperti di Desa Pakis Kecamatan Kunjang Kabupaten Kediri, harus dipupuk agar dapat berkembang lebih baik lagi. Berbagai kegiatan seperti pengelolaan persediaan, strategi pemasaran dan implementasi pembukuan sederhana merupakan serangkaian elemen penting yang diharapkan dapat meningkatkan pertumbuhan UMKM khususnya di Desa Pakis. Tujuan dari dilakukannya Kegiatan Pengabdian Masyarakat melalui Pelatihan Tata Kelola Persediaan, Pemasaran dan Pembukuan Sederhana terhadap Mitra UMKM Desa Pakis adalah memberikan kesadaran akan pentingnya melakukan tata kelola persediaan, pemasaran dan pembukuan sederhana pada berbagai UMKM di beberapa sektor yang ada disana. Selain dosen dari STIESIA selaku pelaksana kegiatan pengabdian masyarakat ini, penyuluhan yang dilakuan juga melibatan mitra yaitu Himpunan Mahasiswa (HIMA) Manajemen STIESIA. Hasil yang diperoleh dari kegiatan pemasaran ini adalah peningkatan pemahaman mitra terhadap tata kelola persediaan, pemasaran dan pembukuan sederhana, dalam rangka meningkatkan nilai produk dan omset penjualan yang dihasilkan.
\end{abstract}

Keywords: Persediaan, Pemasaran, Pembukuan, UMKM, Kediri

\begin{abstract}
The growth of MSMEs (Micro, Small and Medium Enterprises) in Indonesia, especially within remote areas such as Pakis Village, Kunjang Sub-District, Kediri District have to be nurtured in order to further increase their development even better. Numerous activities such as inventory management, marketing strategies and the implementation of simple bookkeeping are an important elements which could improve the development of MSMEs especially in Pakis Village. The aim of this community service through inventory management, marketing, and simple bookkeeping training towards various MSMEs partner in Pakis Village was to enlighten the MSMEs on the importance of inventory management, marketing activities and bookkeeping for their business. Aside from STIESIA's lecturers, this community service activities also involved partnering with STIESIA's Management Students Association (HIMA). The expected result of this community service activities was the increase of MSMEs practitioners understanding on the implementation of inventory management, marketing strategies, and simple bookkeeping so that they would eventually increase their product value and revenue.
\end{abstract}

Keywords: Inventory, Marketing, Bookkeeping, SME, Kediri 


\section{PENDAHULUAN}

Peranan Usaha Mikro, Kecil, dan Menengah (UMKM) pada perekonomian nasional sangat besar hingga mencapai 99,9\% dan penyerapan tenaga kerja mencapai $97 \%$. Jumlah usaha kecil di Indonesia mencapai $93,4 \%$, kemudian usaha menengah $5,1 \%$ sedangkan yang besar hanya 1 persen (Bank Indonesia, 2015). Sehingga tidak mengherankan apabila UMKM dapat menyumbang PDB hingga 60,34\%. Kehadiran para pelaku UMKM merupakan bagian terpenting karena menjadi salah satu motor penggerak terbesar dalam perekonomian di Indonesia. Oleh karena itu penting bagi UMKM tersebut untuk memperoleh berbagai macam pengetahuan yang mampu meningkatkan efiktifitas dan efisiensi bagi usaha yang mereka lakukan.

Kediri merupakan salah satu kota di Jawa Timur yang berkembang pesat sektor UMKMnya. Diawalai dengan menjadi salah satu pusat industri tembakau di Jawa Timur, kini sektor UMKM yang lain di Kediri juga menunjukkan perkembangan yang cukup pesat. Berdasarkan data statistik yang ada, jumlah UMKM di kota Kediri meningkat dari 32 ribu pada tahun 2011 menjadi 39 ribu pada tahun 2016 (Badan Pusat Statistik, 2016). Namun terlepas dari perkembangan pesat tersebut, perlu kiranya dikaji kembali apakah pelaku UMKM khususnya di Desa Pakis, Kecamatan Kunjang, Kabupaten Kediri dalam pengelolaan usahanya, khususnya terkait pemasaran, pengelolaan persediaan dan pembukuan, telah berjalan secara optimal.

Bagaimana mengelola persediaan merupakan salah satu elemen penting dalam keberlangsungan sebuah usaha. Persediaan mencakup bahan mentah, bahan baku setengah jadi, bahan baku yang mendukung proses produksi dan barang jadi (Muller, 2019). Pengelolaan persediaan sangat penting untuk merencanaka kegiatan produksi, mengantisipasi adanya fluktuasi permintaan, menjaga kuantitas persediaan pada saat terjadi kelangkaan bahan baku, menjaga kestabilan harga produk dan membuat harga beli bahan baku menjadi lebih murah ketika pembelian dalam jumlah besar dilakukan (Muller, 2019). Pada umumnya, sebuah perusahaan harus mengelola stok persediaan barang mereka dengan baik untuk mengurangi resiko terjadinya kehilangan barang, kerusakan dan juga kesalahan prediksi pemesanan. Untuk melakukan pengelolaan stok persediaan atau inventaris secara efektif diperlukan cara yang terstruktur. Salah satunya adalah ketika memesan bahan baku. Dalam melakukan pemesanan tersebut, perlu dilakukan perencanaan dan proyeksi yang matang, terutama untuk mencegah terjadinya kekosongan yang menyebabkan pemesanan yang mendadak dan tidak efisien. Oleh karena itu akitivitas pencatatan dalam pengelolaan persediaan menjadi hal yang penting bagi pelaku usaha khususnya UMKM.

Pemasaran sangat penting bagi bisnis apapun, tidak memandang bisnis tersebut besar maupun kecil. Apabila dalam suatu bisnis tidak ada kegiatan pemasaran, maka konsumen tidak akan mengetahui tentang produk yang dihasilkan dari bisnis tersebut dan membuat penjualannya menjadi rendah. Tetapi dengan melakukan pemasaran yang baik, maka akan membuat banyak orang tahu tentang produk usaha yang tengah dilakukan dan memungkinkan banyak konsumen yang tertarik. Ditengah persaingan bisnis yang semakin ketat, UMKM harus memiliki keunggulan dibandingkan dengan pesaing atau pelaku usaha lainnya. Oleh karena itu penting bagi UMKM untuk melakukan kegiatan pemasaran dengan tepat.

Hal lain yang tidak kalah penting untuk menunjang keberhasilan suatu usaha adalah pembukuan. Salah satu kesalahan yang sering dilakukan pengusaha ialah mencampur adukkan keuangan. Pengusaha pemula seringkali kebingungan memisahkan keuangan pribadinya dari keuangan perusahaan. Hal inilah yang akan menimbulkan kerancuan. Tidak sedikit usahawan yang tidak mengetahui berapa keuntungan atau kerugian usaha yang mereka jalankan dikarenakan mereka mencampur adukan biaya dan hasil bisnisnya kedalam satu wadah dan memakainya untuk keperluan sehari-hari. Oleh karena itu penting bagi pengusaha khususnya UMKM untuk melakukan pembukuan secara tepat agar dapat berkembang dan pemanfaatan omset yang didapat menjadi lebih efektif dan efisien. Berdasarkan pemaparan tersebut maka pengabdian masyarakat ini dilakukan untuk memberikan pemahaman dan kemampuan, 
dari UMKM Desa Pakis Kecamatan Kunjang Kapubaten Kediri, dalam melakukan tata kelola persediaan, pemasaran dan pembukuan sederhana.

\section{KAJIAN LITERATUR}

Manajemen persediaan atau pengelolaan persediaan meliputi kegiatan pengembangan, implementasi dan administrasi prosedur, kebijakan dan sistem persediaan (Cox et al., 1991). Dalam pengelolaan persediaan terdapat dua metode, yaitu periodik dimana pencatatan dilakukan setiap tahun dan perpetual dimana pencatatan dilakukan setiap kali terdapat perubahan pada persediaan (Flynn et al., 2014). Pada kegiatan pengabdian ini, pelatihan persediaan yang dilakukan mengacu pada sistem perpetual karena sifat bahan baku dari UMKM yang jumlahnya tidak banyak dan pencatatannya lebih mudah bagi pelaku usaha yang belum pernah melakukan pencatatan persediaan sama sekali.

Definisi dari pemasaran adalah proses sosial dan manajerial dimana individu dan kelompok dapat memperoleh apa yang mereka inginkan melalui proses penciptaan, penawaran dan pertukaran produk yang memiliki nilai dengan pihak lain (Kotler, 2017). Inovasi sangat penting dalam usaha peningkatan kinerja pemasaran dari sebuah usaha. Dengan adanya inovasi pada pemasaran maka, pengusaha khususnya UMKM akan dapat meningkatan nilai jual dari produk yang mereka buat dan membedakan produk tersebut dengan produk kompetitor yang ada pada pasar. Pada kegiatan pengabdian ini, fokus dari pelatihan pemasaran yang dilakukan mencakup labelling, pengemasan dan strategi pemasaran yang lebih baik sehingga dapat meningkatkan omset dari UMKM yang ada di Desa Pakis.

Pembukuan adalah pencatatan tentang transaksi masuk dan transaksi keluar yang terjadi akibat dari aktivitas bisnis yang dilakukan (Bookkeeping, 2020). Meskipun pembukuan yang sederhana mudah untuk dilakukan namun realitanya, banyak sekali UMKM yang ada belum memiliki atau melakukan pencatatan keuangan sama sekali. Ini adalah kasus yang umum terjadi pada sektor UMKM dimana pelaku usahanya hanya berfokus pada perolehan pendapat untuk kebutuhan mereka sehari-hari, sehingga tingkat usaha yang mereka lakukan menjadi sulit untuk berkembang. Berdasarkan paparan diatas maka disusunlah kegiatan pengabdian masyarakat dengan judul: Pelatihan Pengelolaan Persediaan, Pemasaran dan Pembukuan Sederhana untuk UMKM Desa Pakis Kecamatan Kunjang Kabupaten Kediri.

\section{METODE PELAKSANAAN}

Tahapan dan rencana pelaksanaan kegiatan pengabdian masyarakat di Desa Pakis, Kecamatan Kunjang, Kabupaten Kediri adalah sebagai berikut :

1) Melakukan identfikasi calon mitra pengabdian kepada masyarakat

2) Melaksanakan survei lapangan dan kordinasi antara ketua kelompok, anggota kelompok dan mitra himpunan mahasiswa (HIMA) manajemen STIESIA terkait rencana pelaksaan pelatihan melalui kegiatan pengabdian masyarakat di Desa Pakis, Kecamatan Kunjang, Kabupaten Kediri

3) Melakukan persiapan dan menetapkan jadwal pelaksanaan kegiatan pengabdian masyarakat di Desa Pakis, Kecamatan Kunjang, Kabupaten Kediri

4) Mempersiapkan materi pengelolaan persediaan, pemasaran, dan pembukuan sederhana yang akan digunakan pada saat kegiatan pelatihan

5) Menyampaikan materi pengelolaan persediaan dan melakukan pendampingan terhadap proses pengelolaan persediaan

6) Menyampaikan materi pemasaran khususnya terkait dengan pengemasan, labelling dan banner yang memberikan keunikan dan dapat menarik lebih banyak konsumen produk UMKM yang diperjualbelikan

7) Menyampaikan materi pembukuan sederhana dan melakukan pendampingan terhadap proses pembukuan sederhana 


\section{HASIL DAN PEMBAHASAN}

Kegiatan pelaksanaan pengabdian masyarakat dilakukan pada hari Selasa, tanggal 11 Februari 2020, pukul 10.00 WIB bertempat di Balai RW Desa Pakis, Kecamatan Kunjang, Kabupaten Kediri. Kegiatan ini diikuti oleh 25 pelaku UMKM, 4 orang narasumber dan 30 orang mahasiswa sebagai pendamping yang ikut terlibat pada kegiatan Pengabdian Masyarakat.

Fokus pada kegiatan pelatihan dan diskusi permasalahan pada pelaksanaan kegiatan pengabdian kepada masyarakat yang dilakukan mencakup:

1) Penerapan pengelolaan persediaan demi meningkatkan nilai jual dari produk UMKM Desa Pakis agar lebih efektif dan efisien

2) Formulasi kegiatan pemasaran yang lebih baik, melalui labelling, pengemasan dan penerapan strategi pemasara yang lebih baik dalam upaya meningkatkan omset dari UMKM yang ada di Desa Pakis

3) Penerapan pembukan sederhana sebagai solusi permasalahan pencatatan keuangan yang sebelumnya tidak dilakukan oleh UMKM yang ada di Desa Pakis, sehingga keuntungan yang didapat menjadi kurang optimal

Rincian pelaksanaan kegiatan inti pengabdian masyarakat oleh Tim Pengabdian Masyarakat bersama dengan mitra HIMA Manajemen STIESIA Surabaya mencakup sebagai berikut:

1) Pembukaa oleh pemandu acara dari pihak HIMA Manajemen STIESIA Surabaya

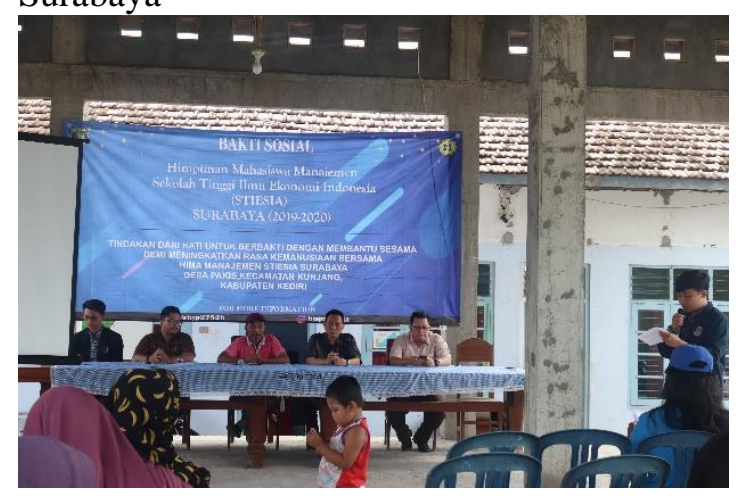

2) Sambutan dan Pemaparan materi secara umum

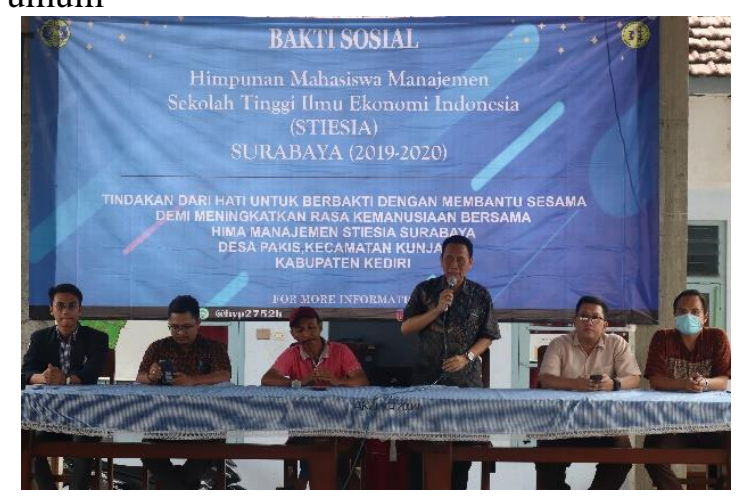

3) Pemberian materi pemasaran

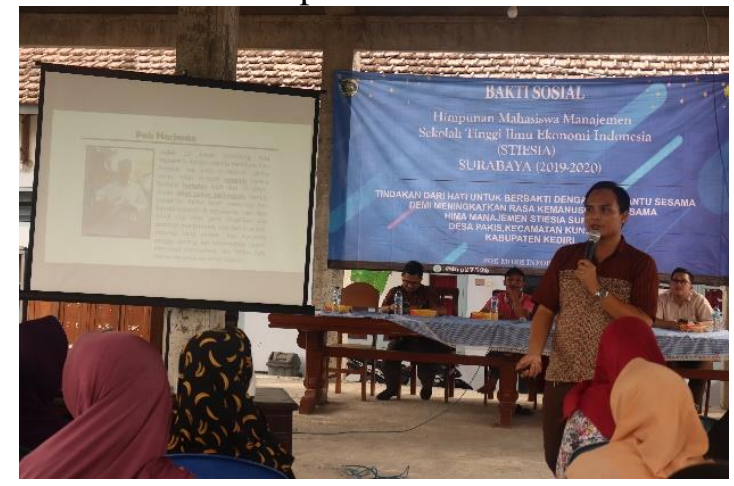

4) Pemberian materi pengelolaan persediaan

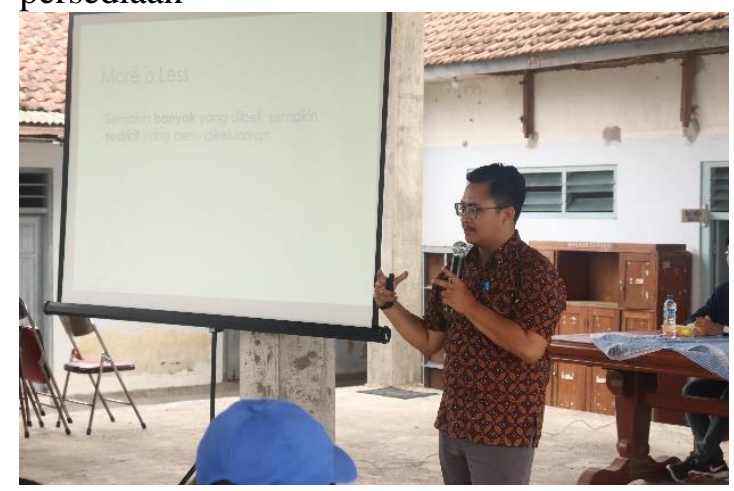

5) Pemberian materi pembukuan sederhana

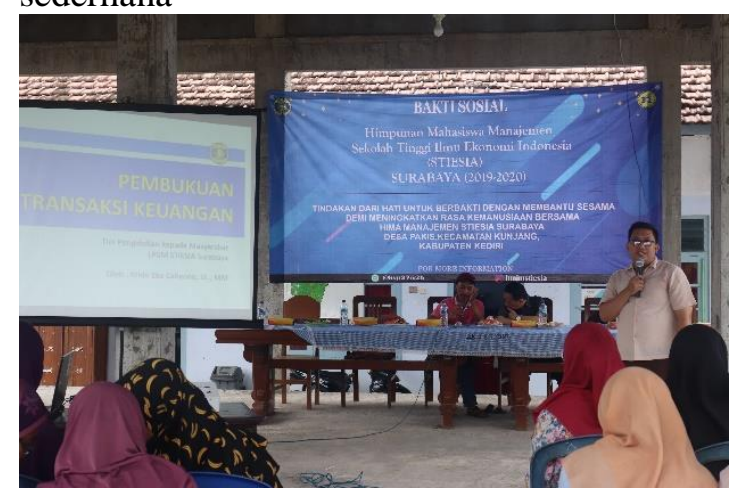

6) Foto Bersama segenap perangkat desa, tim pengabdian masyarakat dan HIMA Manajemen STIESIA Surabaya 


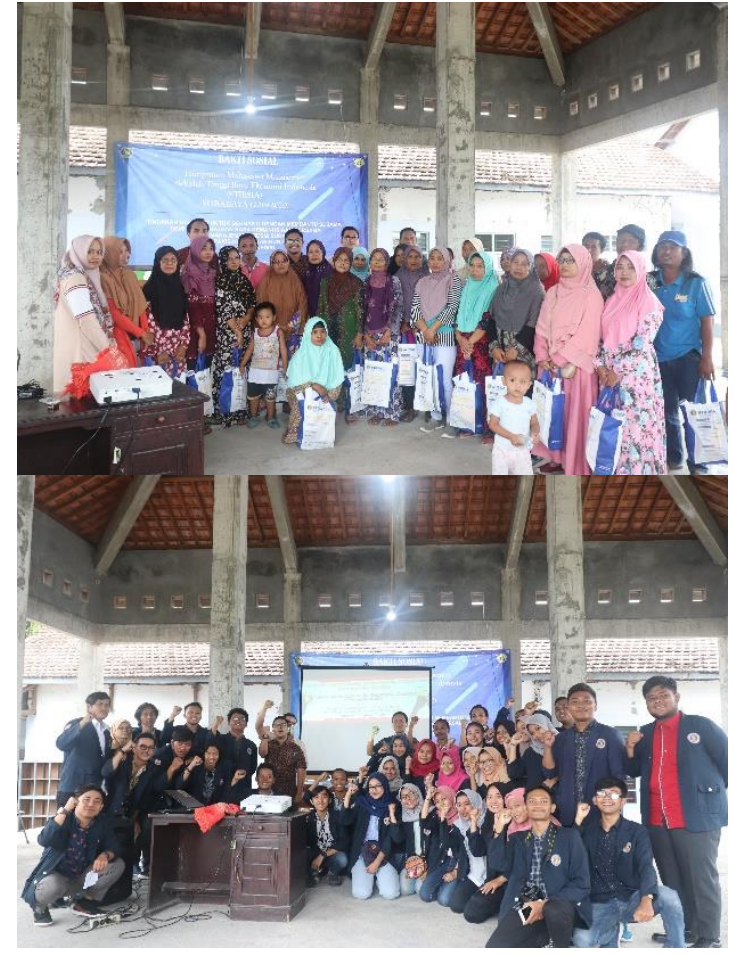

\section{KESIMPULAN}

Berdasarkan kegiatan pengabdian masyarakat di Desa Pakis terkait dengan implementasi pemasaran, pengelolaan persediaan dan pembukuan sederhana, dapat diperoleh kesimpulan berikut:

1) Peserta kegiatan pengabdian masyarakat memahami materi yang akan diberikan secara umum

2) Peserta kegiatan pengabdian masyarakat memahami penerapan strategi pemasaran melalui banner produk, labelling dan pengemasan yang lebih baik dalam rangka meningkatkan nilai jual dari UMKM yang mereka lakukan

3) Peserta kegiatan pengabdian masyarakat memahami penerapan pengelolaan persediaan yang lebih baik dalam rangka meningkatkan omset dan keuntungan dari UMKM yang mereka lakukan

4) Peserta kegiata pengabdian masyarakat memahami manfaat beserta proses pembukuan sederhana dalam rangka meningkatkan keuntungan dari UMKM yang mereka lakukan

\section{UCAPAN TERIMA KASIH}

Untuk kesuksesan dan kelancaran program pengabdian kepada masyarakat yang telah dilakukan di Desa Pakis, Kecamatan Kunjang, Kabupate Kediri ini, tim pengabdian kepada masyakarat mengucapkan terima kasih kepada beberapa pihak:

1) Ketua STIESIA Surabaya yang telah memberikan ijin berlangsungnya kegiatan pengabdian masyarakat

2) Kepala LPPM STIESIA Surabaya yang telah memfasilitasi berlangsungnya kegiatan pengabdian masyarakat

3) Perangkat Desa di Desa Pakis, Kecamatan Kunjang, Kabupaten Kediri yang telah memberikan ijin dan menyediakan tempat berlangsungnya kegiatan pengabdian masyarakat

4) Mahasiswa HIMA Manajemen STIESIA yang telah membantu kelancaran proses pelaksanaan kegiatan pengabdian masyarakat

5) Seluruh peserta kegiatan pengabdian kepada masyarakat dari UMKM Desa Pakis, Kecamatan Kunjang, Kabupaten Kediri atas antusiasmenya mengikuti kegiatan dari awal hingga akhir

\section{REFERENSI}

Badan Pusat Statistik. (2016). Sensus Ekonomi 2016.

Bank Indonesia. (2015). PROFIL BISNIS USAHA MIKRO, KECIL DAN MENENGAH (UMKM).

Bookkeeping. (2020). Oxford Online Dictionary.

Cox, J. F., Tate, C. E., Scarpello, V., \& Hoy, F. (1991). Small Business Management and Entrepreneurship. PWS-Kent Publishing Company.

Flynn, D., Koornhof, C., Arendse, R., \& Muriro, E. (2014). Fundamental Accounting (6th ed.). JUTA \& Company Ltd.

Kotler, P. (2017). Principles of Marketing (17th Edition) (17th ed.). Pearson.

Muller, M. (2019). Essentials of Inventory Management (3rd ed.). HarperCollins Leadership. 